\title{
Formation of the transport model of urban agglomeration
}

\author{
Alexei Levashov ${ }^{1, *}$ \\ ${ }^{1}$ Irkutsk National Research Technical University, 664074, Lermontova str., 83, Irkutsk, Russia
}

\begin{abstract}
The paper is devoted to the problem of estimating the transport demand for movements in the cities, taking into account the transportation inside the urban agglomerations. An approach to the formation of a transport model of urban agglomeration based on the combination of several models of transport demand is considered in the article. The author proposes a methodology for estimating the distribution of movements between cities within the agglomeration at the time.
\end{abstract}

The search for optimal solutions for the development of urban areas requires an appropriate information base, one of the most important components of which is the transport model. The transport model of the city is a geo-information database that takes into account the characteristics of the city's transport system and the features of using the urban area it serves. Based on the parameters of the calculated transport areas, such as the population size, the number of places of employment, etc., and taking into account the mobility characteristics of the population, the transport model allows estimating the number of movements that residents make. Thus, the main purpose of the transport model is to estimate the transport demand for movements, taking into account such characteristics as:

- time of the commencement of movements;

- mode of movements;

- route of movements;

- the time spent on movements in general and its individual components, including the time equivalents of the cost of travel, parking, etc. (the generalized cost of movements);

- appearance of new elements of the transport system (new road sections, bridges, etc.;

- development of the urban areas.

Today, the problem of "uncontrolled proliferation" of territories without taking into account preliminary estimates of subsequent additional loads on the city's transport system is the feature of many Russian cities. One of such examples is the city of Irkutsk, the suburban territory of which (Irkutsk district), taking into account the planned development, by 2030 will have about 200 thousand residents, that is, almost a third of the population of Irkutsk. Thus, a full-scale planning of the development of the transport system of Irkutsk is impossible without taking into account the Irkutsk district.

Considering the problem of assessing the transport demand of Irkutsk, it is impossible not to take into account its external links with neighboring cities (Angarsk, Shelekhov), which

\footnotetext{
* Corresponding author: alexey.levashev@tl-istu.com
} 
also affect the loading of the urban transport system. The ability to take into account such transport links allows moving to problem solving, including:

- formation of a system of intra-agglomeration high-speed bypass roads;

- development of long-distance public transport system;

- increasing the attractiveness of the rail transport as an intercity transport;

- formation of a unified network tariff system, etc.

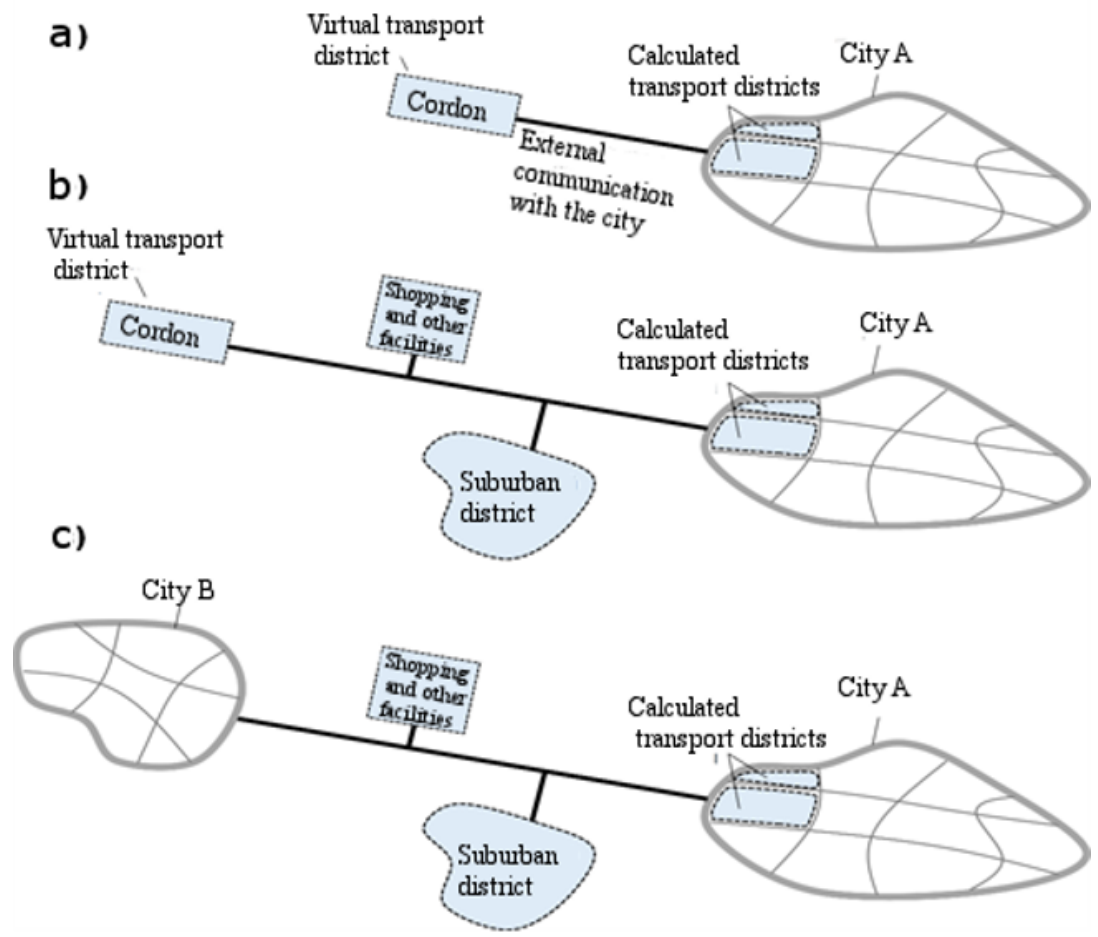

Fig. 1. Options of ways of modeling of external transport communications with a city: a) - by means of a virtual area-cordon; b) - with the detailing of the adjacent territories along the transport corridor and the separation of the neighboring city (as a part of the metropolitan area) in the form of a virtual cordon district; c) - with the detailing of adjacent territories along the transport corridor and the neighboring city within the agglomeration.

The authors of different countries [1-21] have analyzed a range of problems associated with the assessment of traffic conditions and transport demand for movement within the boundaries of separate sections of the road network and cities in general. In particular, the author of this article has considered some cases of the demand estimation within the boundaries of the urban transport corridor [4], using modern geo-information source data necessary for transport modeling [13]. At the same time, methods for modeling the transport systems of the urban agglomerations are not yet analyzed in details in the specialized literature. At the same time, in Russia, only the models of transport demand for intra-urban movements are currently used. 


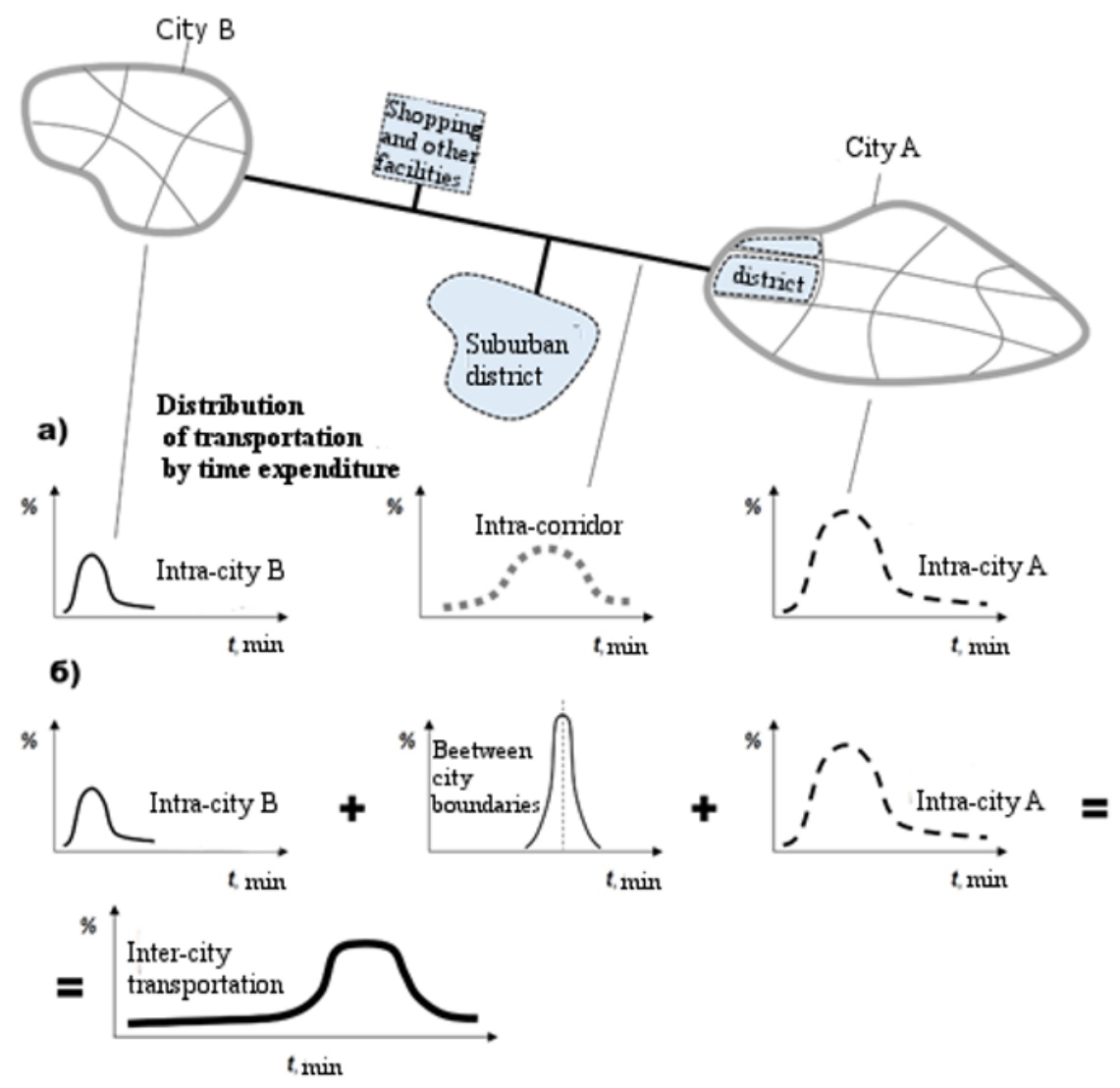

Fig. 2. Formation of the function of gravity (the dependence of the probability of movements on time): a) - the choice of the gravity function for each element of the transport system; b) - the formation of the gravity function separately for movements between cities.

In order to develop approaches to the assessment of transport demand for movements within the agglomeration, the transport system is proposed to be presented in several ways (Figure 1) when:

- External links are presented as a virtual cordon district;

- The city is connected with external communication in the form of a suburban transport corridor;

- Two cities are connected by a suburban transport corridor.

The second of these methods allows taking into account in detail the movements formed along the corridor, and the third - in addition, allows considering the movements between individual cities. The third method is especially attractive for solving problems of increasing attractiveness of public transport for long-distance traffic.

To build a transport model of the agglomeration, it is proposed to use a combination of transport demand models, including: individual demand models within each of the cities, a demand model within a suburban transport corridor, demand models for movements to the city from areas along the transport corridor (and vice versa), and a demand model for the movements between the two cities. 

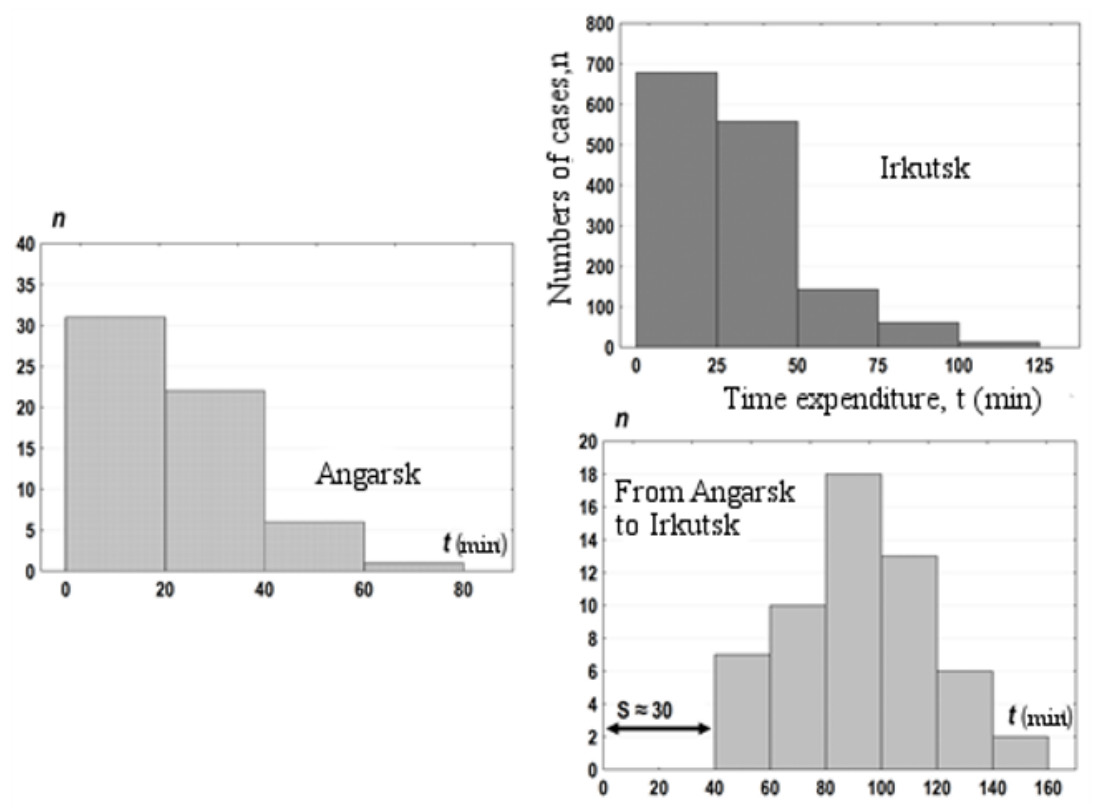

Fig. 3 Distribution of movements over time spent, on the results of processing the questionnaire survey of the population in the cities of the Irkutsk agglomeration (without division by the modes of movements).

The Figure 2 conditionally presents the gravity functions in the composition of the mentioned above models of demand for the movements. The gravity function within the transport corridor is proposed to be evaluated on the basis of special methods for reconstructing transport correspondence matrices [13 - 14, 17, 20]. The gravity function between cities is proposed to be formed taking into account the existing functions of gravity (usually estimated by the results of the population questionnaires) and the parameters of the transport system that determine the time spent on traveling between the boundaries of the cities.

The Figure 3 presents the results of the household questionnaires in the cities of the Irkutsk agglomeration. The analysis of the results of the population survey confirmed the presence of a shift in the actual distribution of movements at the time costs associated with an increase in the expenditure of time for all long-distance traffic.

As a result, as the main conclusion, it is proposed to conduct additional studies that will allow presenting the formalized approach to the creation of the gravity functions for the longdistance movements, taking into account particular modes of transportation and the parameters of the transport system that determine the mutual distance between the cities of the metropolitan area.

\section{References}

1. V. A. Gudkov, N. V. Dulina, V. V. Tokarev, Freight and Passenger Carrier, 4, 29-33 (2009)

2. E. N. Kovaleva, Journal of the University of Water Communications, 3, 171-175 (2011)

3. A. G. Levashev, Izvestiya Vuzov. Investments. Building. Real Estate, 6, 108-115 (2014)

4. A. G. Levashev, Modern trends in the development of urban systems: materials of the 
international scientific conference, 221-223 (2015)

5. A. Yu. Mikhailov, A. G. Levashev, M. I. Sharov, Modern methods for assessing the quality of traffic management in cities (Irkutsk, 2015)

6. E. S. Prelovskaya, A. G. Levashev, Transport model of the Irkutsk agglomeration (LAP LAMBERT Academic Publishing, Saarbruecken, 2014)

7. M. G. H. Bell, Transportation Research B, 25B (1), 13-22 (1991)

8. E. Cascetta, S. Nguyen, Transportation Research, 22B, 437-455 (1988)

9. G. Chang, J. Wu, Transportation Research-B, 28B, 141-160 (1994)

10. Di Di, Yang Dongyuan, Advances in Mechanical Engineering, 7(11), 1-10 (2015)

11. Teng Jing, Lai Xiong-fei, Advances in Mechanical Engineering, 9(7), 1-14 (2017)

12. A. Levashev, E. Prelovskaya, Organization and traffic safety management in large cities, 523-528 (2016)

13. A. Levashev, Organization and traffic safety management in large cities, 406-411 (2016)

14. A. Levashev, A. Mikhailov, I. Golovnykh, Proceedings of the VIII-th international conference on "The Sustainable City VIII," 1067-1076 (2013)

15. A. Levashev, A. Mikhailov, M. Sharov, Proceedings of the international conference on "Energy Production and Management in the 21st Century - The Quest for Sustainable Energy," 1, 651-660 (2014)

16. A. V. Bogoviz, Y. V. Ragulina, N. V. Sirotkina, Advances in Intelligent Systems and Computing, 622, 597-602 (2018)

17. M. Maher, Transportation Research, 20B, 435-447 (1983)

18. M. Nawaz, S. Somenahalli, A. Allan, Road \& Transport Research, 26, 62-74 (2017)

19. M. Sharov, A. Levashev, A. Mikhailov, WIT Transactions on Ecology and the Environment, 1, 651-660 (2014)

20. N. J. Van Der Zijpp, R. Hamerslag, Transportation Research Records, 1443, 54-64 (1994)

21. A. Vulevic, D. Macura, D. Djordjevic, R. A. Castanho, Transylvanian Review of Administrative Sciences, 123-143 (2018) 